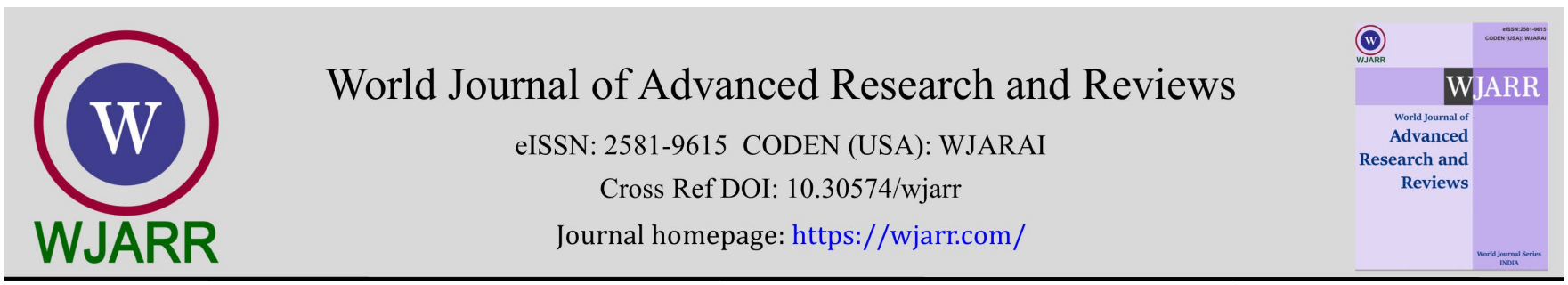

(REVIEW ARTICLE)

Check for updates

\title{
Ageing process and policosanol effects
}

José Illnait-Ferrer, Julio César Fernández-Travieso *, Yenney Reyes-Nuñez and Alicia de la Caridad DuquesneChávez

Clinical Trials Unit, National Centre for Scientific Research, Havana, Cuba.

World Journal of Advanced Research and Reviews, 2021, 12(02), 273-283

Publication history: Received on 19 May 2021; revised on 30 September 2021; accepted on 02 October 2021

Article DOI: https://doi.org/10.30574/wjarr.2021.12.2.0242

\begin{abstract}
The fundamental concepts of the aging process are exposed: Its dimension as a health problem, aspects related to its repercussion from the social point of view, and Its influence on aspects that can affect the normal development of contemporary society. The roles of genetics, cellular and biochemical processes that concur in the development of aging is analyzed, making special reference to the role of Adenosine Mono Phosphate Kinase [AMPK]. activation in the regulation of the aging process and the participation of mechanisms for its activation. It is concluded that Policosanol is a medicament of natural origin that could be proposed as candidate to be used for a healthy aging, based on the results of various investigations in experimental models and data obtained from different clinical trials.
\end{abstract}

Keywords: Policosanol; Again process; Clinical trials; Adenosine Mono Phosphate Kinase [AMPK].; Molecular mechanism

\section{Introduction}

\subsection{Definition}

Aging is an inevitable, inexorable and irreversible process, commonly defined as the functional decline that occurs during the life of all living organisms, which is characterized by a progressive loss of physical and functional integrity that precedes death [1].

\subsection{Aging as a health problem}

For the first time in history, most people have reached a life expectancy of more than 60 years. Twenty \% of all humanity will reach that age in the very near future, and by then, the consequences on health, health systems, and the workforce will be very adverse. That is because aging results a state of vulnerability to worsening conditions related to climate change, emerging infectious diseases or infectious diseases resistant to antibiotics, but above all, due to the increasing incidence of chronic non-communicable diseases (CNCDs) that frequently accompany the aging process. All of this implies an enormous challenge for the whole of society, and that is why it is necessary to ensure that the aging process runs by the healthiest way possible. To achieve this objective, it is very important to eliminate the conditions of potential risks of CNCDs [2].

Even when life expectancy increases in the developed world, due to the undeniable advances in the treatment of CNCDs in contemporary medicine, these require costs in treatments that must be applied during the rest of the lives of those who suffer CNCDs, but only to maintain a relative state of health without being cured. Thus, despite the treatments,

\footnotetext{
${ }^{*}$ Corresponding author: Julio César Fernández-Travieso

Head of Clinical Trials Unit, National Centre for Scientific Research, Havana, Cuba.
}

Copyright (C) 2021 Author(s) retain the copyright of this article. This article is published under the terms of the Creative Commons Attribution Liscense 4.0. 
these diseases are responsible for millions of deaths, which have come to constitute more than $60 \%$ of all causes of death, with a tendency to increase by $17 \%$ in 2025 [3].

\subsection{Some molecular and physiological mechanisms related to the aging process}

The molecular mechanisms associated with the aging process are not yet fully understood in their all magnitude and depth. Advances in knowledge have only just begun to reveal the complex mechanisms involved in its development.

Aging is associated with a gradual accumulation of damages not only molecular, but also cellular and homeostatic, which conditions the alteration of physiological processes leading to a decline in physical and mental capacity. These alterations usually appear gradually, discreetly, isolated or also simultaneously and even at a relatively early in life [4].

The different changes related to aging do not necessarily occur at the same age, and not always they behave in the same way in all individuals, due to the random influence of the phenomena that favor the aging process, such as: the various levels of environmental contamination, the different harmful habits and unhealthy behaviors that are particulars for each individual [4].

Various evidences indicate that the organismal imbalance caused by metabolic disorders associated to unhealthy nutritional habits and sedentary lifestyle, among others, exert a negative influence on the aging process, quality of life and survival. Thus, the accumulation of adipose tissue, caused by not healthy nutritional habits and sedentary lifestyle, is related to different metabolic disorders such as metabolic syndrome, dyslipidemia or diabetes mellitus, which negatively affect longevity in various tissues and organs. So, because the body's energy needs are determined by the balance between fat-free mass and the level of physical activity, when the level of ingested calories exceeds the body's needs, they accumulate as fat in adipose tissue and consequently, obesity and weight gain occur, conditioning the appearance of damages that are expressed at the cellular level by the increase in reactive oxygen species, which in turn promote aging [4].

On the contrary, caloric restriction (without reaching malnutrition), promotes longevity in a wide spectrum of experimental models that range from microorganisms to the human species. Caloric restriction protects against excessive adiposity, which prevents cardiovascular diseases, insulin resistance, type II diabetes, neurodegenerative diseases and cancer, which are among those that appear more frequently with advancing age. Studies at the molecular level suggest that caloric restriction is a process regulated by Sirtuin 1 (Sirt 1), which is a member of a family of protein deacetylases that are activated by AMPK $[5,6]$.

On the other hand, maintaining adequate and systematic physical activity is associated with delayed mortality, which has been proven in elderly patients, even when they are already very weakened, and even with severe illnesses. This indicates the importance of practicing physical activity as part of the medical indication to control the aging process. It is considered that the increase in physical activity is the only measure capable to attenuate the progressive decline in muscle mass and strength, since it acts against the progressive decrease in the volume and function of the muscle mitochondria, as well as on the inflammatory state that is produced in muscle fibers during the aging process [7].

Caloric restriction and increased physical activity are considered pillars for the development of healthy aging. The molecular mechanism that constitutes the starting point to explain the effect the two recommendations is because by bough ways AMPK is activated [7].

\subsection{Genetic factor}

As a response to the metabolic and molecular disorders that appear during the aging process, the genome sets in motion mechanisms that tend to preserve functional homeostasis, biochemistry and cell biology to control the evolution of those disorders [8].

When considering the genetic bases of longevity, it is necessary to bear in mind that the genome is the genetic inheritance of the ancestors, while the epigenome would be represented both by the aforementioned modifications of the environment and harmful habits. On the contrary, those habits that are capable to maintain the healthy course of aging and can favorably modify various negative factors [9].

It has been suggested that those individuals who have already reached the age of 70 are those who have managed to "escape" from CNCDs. As age advances, the genetic factor begins to take a greater importance, which is considered heritable between 15 and 40\%. In these sense, it is suggested that such heritability manifests itself more clearly in those 
who have reached ages over 90 years, in which the genetic factors that determine longevity are evidently stronger, especially if they have been inherited by paternal ancestors [9].

Being genetically predetermined the approximate age in which the death occurs, it has been said that: "it is not a matter of prolonging the years of life but, mainly, of giving more life to the years". In this way, developing preventive measures that modify the epigenome in a positive sense, with the aim that the aging process proceeds in a healthy way, could be a good strategy for the prevention of CNCDs, as a whole, probably more effective and economically supportable than if those were treated each of them separately [9].

It is considered that the number of genes that could be related to longevity is about 500, of which, only a small number of them have been studied. One of those gen is the polymorphism of the leukocyte antigen, which is over-represented in long-lived Okinaguens in relation to the younger controls. It has also been observed that there are different polymorphisms in French and German centenarians compared to young people, in the genes that encode the synthesis of Apolipoprotein E, Apolipoprotein A and angiotensin converting enzymes [9].

Fork head box 0 (FOXO) 1, 3, 4, and 6 are a family of proteins that modulate the expression of genes involved in apoptosis, the cell cycle, DNA damage repair, oxidative stress, cell differentiation, and glucose metabolism, among many others cellular functions that are associated with healthy aging. The activity of these proteins is regulated by various mechanisms, but mainly by the activity of the Sirt proteins, which in turn are regulated by AMPK. The lack of regulation of FOXO proteins can lead to diseases such as cancer [10].

These FOXO proteins are transcription factors that play an important role in the extension of life and are related to dietary restriction. A better understanding about the way by which FOXO proteins act, could help to clarify the mechanisms by which aging is a risk factor for various diseases, on the other hand, it could increase the possibility for the development of a wide spectrum of drugs to prevent those diseases related to aging $[11,12]$.

\subsection{Aging at the molecular and cellular level}

The fundamental function of AMPK is the homeostatic control of metabolic energy necessary for many metabolic processes. Increased AMPK activity can extend life span in mammals because it regulates autophagy, improves cell function, induces mechanisms that increase resistance to stress, and controls the inflammatory response. On the contrary, the decline in AMPK activity is associated with aging, increased oxidative stress, reduced autophagy of damaged cell organelles, appearance of inflammation, favors various metabolic disorders, and consequently the loss of capacity for the regeneration of stem cells in tissues, resistance to stress and good cell function, which are indicators of health and prolongation of life $[13,14]$.

At present, there is the objective to study the polymorphism of genes that encode proteins involved in different aspects related to longevity at the cellular level, such as: mitochondrial and peroxisomal dysfunction, resistance to oxidative stress, DNA methylation, control of the cell cycle, the proteolysis of misfolded proteins, changes in membrane lipids, the shortening of telomeres and the decline of autophagy among other changes associated with aging $[15,16]$.

A consensus has been reached that, at the cellular level, progressive DNA damage and the decline of the mitochondria are mainly responsible for natural aging. However, this does not diminish the importance of the effect that peroxisome dysfunction produces on the normal aging process, since these organelles are integrated into an endomembrane system that governs cellular aging by modulating the levels of non-esterified fatty acids. and diacylglycerol. Furthermore, there is a functional interrelation between peroxisomes and mitochondria from the point of view of their metabolic activity. In this sense, both organelles share aspects related to oxidation-reduction mechanisms, which constitutes the basis of one of the best known theories to explain the aging process. Peroxisomes functions as a source, as a sink, or also as a target for reactive oxygen molecules. However, it is considered that their participation in the aging process has been underestimated [17].

With advancing age, both peroxisomes and mitochondria can deteriorate and autophagy constitutes the only defense mechanism against the accumulation of defective mitochondria and peroxisomes, which, once damaged, promote aging. Although, however, this autophagy mechanism can also fail with increasing age. 


\section{Regulatory effect of very long chain fatty acids (VLCFA) on the aging process}

Experimental data suggest that VLCFA play an important role in the regulation of telomere length, which are necessary actors of aging and longevity. In these experiments, it has been shown that the deletion of elongase (an enzyme that intervenes in the synthesis of VLCFA) in mice leads them to death a few hours after birth [18].

The deterioration of peroxisomes and their malfunction can lead to an increase in reactive oxygen species since, by decreasing the $\beta$ oxidation of VLCFA in peroxisomes, they accumulate in excess leading to a decrease of plasmalogen synthesis [19].

Among the multiple functions, plasmalogens are able to trap free radicals, as well as neutralize hypochlorous and hypobromous acids, highly oxidizing, which are produced by leukocytes during inflammation, which is a condition closely linked to aging. Besides that, Plasmalogens also inhibits the synthesis of nitric oxide. In addition, the reduction of plasmalogen production alters the composition of cell membranes, their structure, fluidity and function. ${ }^{19}$ The limitation of VLCFA synthesis is also capable of inducing the formation of unfolded proteins, a phenomenon closely associated with aging [20].

Patients with adreno-leuko-dystrophy, whose shows a genetic deficiency of peroxisomes, suffer from serious metabolic disorders, caused by poor metabolism of VLCFA, exhibiting severe central and peripheral nervous system involvement, as well as other symptoms that profoundly affect their health, and that is why they die at early age [21]. On the contrary, it has been shown that diets rich in VLCFA and also in polyunsaturated fatty acids (DHA, EPA) can increase the proliferation of peroxisomes and enzymes that participate in lipid metabolism [22]. It is significant that saturated and unsaturated VLCFA are peroxisome proliferator ligands $\alpha$ (PPAR $\alpha$ ), which play a very important role in the induction of transcription of multiple peroxisomal enzymes [23-26].

It has been suggested that the protective effects of VLCFA contained in the diet could occur via regulation of the SIRT SREBP-1 - histone H3 axis, which leads to the consideration that VLCFA are involved in genetic processes related to control of aging [6].

The levels of serum plasmalogens, derived from VLCFA, show a positive and significant correlation with the functionality and plasma concentration of High-Density Lipoprotein- Cholesterol (HDL-c) [27].

HDL tends to decrease with advancing age and as a consequence increases the incidence of coronary stenosis and abnormal glucose tolerance, all of which is also associated with a decrease in plasmalogen in HDL-c and with a decrease in its antiapoptotic activity [28].

On the contrary, the elevation of the HDL-c concentration is associated with longevity, as demonstrated in a prospective, national cohort study, which included 7766 elderlies between 65 and 74 years of age. In this study, 1921 deaths occurred in a period of 5.9 years. The risk of all-cause mortality was associated with an HDL-c level $<61 \mathrm{mg} / \mathrm{dl}$. While the minimum mortality was associated with HDL-c figures $>71 \mathrm{mg} / \mathrm{dl}$ in a range between $61 \mathrm{and} 85 \mathrm{mg} / \mathrm{dL}$ [29]. All of which suggests an important role of HDL-c, possibly associated with its plasmalogen content and reducing the velocity of the aging process.

\section{Effects of policosanol in different aspects associated with the aging process}

Policosanol is a mixture of very long chain fatty alcohols (VLCFAl), extracted from Cuban sugar cane, originally indicated to improve the lipid-profile. Policosanol reduces the serum concentration of total cholesterol, triglycerides, Low Density Lipoprotein-Cholesterol (LDL-c), and Very Low Density-Cholesterol (VLDL-c) but, on the contrary, increases HDL-c serum concentration and improves its functionability. It was demonstrated that policosanol exert those effects by activating AMPK [30-32].

Starting from the hypothesis that improving the functionability of HDL-c it can be stimulated the cell growth, as well as tissue regeneration. And taking into account that the improvement in the functionality of HDL-c is associated with the effects of cell regeneration, vasodilation, anti-thrombotic and anti-apoptotic and that policosanol notably increases the concentration of plasmalogen and paraoxonase in HDL-c; a study was carried out where an increase in the growth rate of brain gliomas cells and the regeneration of the tail was observed in an experiment with zebrafish treated with reconstituted HDL-c and enriched with policosanol. This result is considered as an antiapoptotic and tissue regeneration 
action, which was accompanied by a decrease in the production of reactive oxygen species, all of which could explain longevity, attributable to the improvement in HDL-c functionality [33-35].

It was also confirmed that Policosanol also increased plasmalogen concentration in LDL-c and for this reason the oxidation of LDL-c is also inhibited. Plasmalogen content, synthesized in the peroxisome from VLCFAL that make up policosanol, also contributes to the antioxidant activity of HDL and LDL [36,37].

In some of these experiments, VLCFA and VLCFAL have similar effects. The similarity in the effect of VLCFAL and VLCFA could be explained because both molecules convert into each other according to the metabolic cycle described by Rizzo in the endothelial reticulum [38].

The anti-aging effect of Policosanol was also observed in a randomized, double-blind, placebo-controlled clinical trial involving 1,470 women and men between 60 and 80 years of age for 3 years. This test revealed a significant decrease in total cholesterol, LDL-c and to a lesser extent triglyceride, which was accompanied by a significant elevation of HDL-c. During the trial, 23 participants died due to different CNCDs: 19 in the placebo group (2.6\%) and 4 in the group treated with policosanol $(0.5 \%) \mathrm{p}<0.001$, one of whom died due to a traffic accident [39].

\section{Effects of policosanol related to the aging process}

\subsection{Anti-inflammatory effects}

With the increase in human life expectancy, individuals are exposed for a longer time to different antigens that, together with the aging of the immune system, favor the establishment of a low intensity chronic inflammatory state called "inflammaging". The most important goal of researchers studying inflammaging is to develop effective interventions to improve inflammation. However, only a small fraction of these contributions have managed to have clinical applications [40].

Recent studies have shown that AMPK exerts anti-inflammatory effects through the activation of Sirt1, PGC1 $\alpha$, FOXO3a and p300, in addition to downregulating several proteins related to the inflammatory process such as NF-kB and AP-1, which is why, the AMPK activation has been a suggested mechanism as a therapeutic target to treat inflammation and diseases related to inflammatory processes [41]. On the other hand, there has been evidence that deletion of AMPK $\alpha 1$ in glial cells of mice develops mitochondrial dysfunction and a pro-inflammatory response [41].

It has been shown, in experiments with rats, that Policosanol prevents aspects of the inflammatory process such as the development of foam cells in granulomas induced by carrageenan (extravascular medium), evidencing its antiinflammatory effect in the improvement of lesions of the intima in the aorta [42]. Moreover, it has been also shown antiinflammatory effects in patients with subclinical inflammation, [43]. in obese women [44]. and in patients with hyperlipidemia [45].

\subsection{Antiapoptotic effects}

Policosanol treatment significantly decreases the circulating endothelial cell count induced by sodium citrate injection in animal models [46]. It has been shown that Policosanol, in addition to preventing endothelial damage, significantly reduces the thickness of the intima in rabbit arteries previously damaged by forceps [47]. The experimental results were confirmed in a double-blind, controlled clinical trial in hypercholesterolemic elderly patients, treated with policosanol, in whom a reduction in circulating endothelial cells was observed [48].

Another clinical trial in the elderly confirms that policosanol, in addition to regulating the level of serum lipids, improves endothelial cell function and decreases platelet aggregation by adenosine diphosphate, which could slow the progress of atherosclerotic disease [49].

\subsection{Antioxidant effects}

When Policosanol is administered orally (100 and $200 \mathrm{mg} / \mathrm{kg}$ ) to rats, a decrease in lipid peroxidation is observed in the serum of these animals for 4 weeks; thiobarbituric acid formation in microsomes isolated from rats is significantly decreased by $50 \%$; decreases hyperlipidemia as well as oxidative stress in KKA mice with type II diabetes as well as significantly increases $(20.9 \%)$ the latency time to initiate $\mathrm{Cu}+2$-induced LDL peroxidation, while increasing total antioxidant activity plasma $(24.2 \%)(\mathrm{p}<0.05)$ in a double-blind trial [50-52]. 
Another clinical trial in the elderly confirms that policosanol, in addition to regulating the level of serum lipids, improves endothelial cell function and decreases platelet aggregation by adenosine diphosphate, which could slow the progress of atherosclerotic disease [53].

\subsection{Effect on the reduction visceral fat and of body weight}

It has been observed that adding octacosanol (the most abundant component of Policosanol) to a high-fat diet suppresses peripheral renal fat in experimental animals and concludes that octacosanol and Policosanol are powerful anti-obesity molecules that increase the activity of brown fatty tissue and therefore increase energy expenditure and reduce body fat [54].

The decrease in body weight was the most reported event (24.4\%) in a post-marketing surveillance study involving 27,879 patients [55].

Another drug-epidemiological study also showed the reduction in body weight as the majority report among the collateral effects of Policosanol [56]. Notwithstanding these results, it would be of interest to carry out clinical trials especially aimed at confirming the reduction in body weight and other anthropometric measurements in normal weight and obese individuals.

\subsection{Effect on physical activity}

Physical inactivity has a significant impact on health around the world. Eliminating physical inactivity would eliminate $6 \%$ to $10 \%$ of the major noncommunicable diseases, such as cardiovascular disease; type II diabetes; metabolic syndrome, as well as lung and colon cancer and increases life expectancy [57].

In animals fed with policosanol, the amount of voluntary physical activity was significantly higher and in humans, treatment with Policosanol plus omega 3 administered to eighteen karateka showed a reduction in reaction time and increased the feeling of vigor [58].

A nutritional supplement that mainly contains Policosanol (Vasoactol), used in Cuba for aged people or with special pathophysiological conditions, significantly increased VO2 max (maximum oxygen consumption), mean power and total exercise time in patients treated in relation to placebos in a double-blind trial [59]. Furthermore, a mixture of VLCFAL extracted from Cuban sugar cane wax (D-003), improved V02max, decreased pain and increased the perception of health (Euro-Qol score) as well as cardiovascular capacity (Specific Activity Scale) [60]. The exposed results suggest a facilitating effect of the development of physical activity.

\section{Effects of policosanol treatment on some CNCDs}

\subsection{Ictus}

A dose of $200 \mathrm{mg}$ of Policosanol protected Mongolian gerbils from death due to cerebral infarction induced by carotid ligation [61].

A meta-analysis was performed to study the evidence regarding the relationship between VLCFA ingestion and risk of stroke that included 476,569 individuals with no history of stroke and 11,074 with a history of stroke. The data analysis revealed that the ingestion of VLCFA is inversely associated with the risk and stroke mortality [62].

The addition of Policosanol to conventional therapy in the treatment of stroke patients was able to significantly improve neurological recovery compared to patients treated with conventional therapy. In patients treated with Policosanol, a better response of oxidative variables and serum lipid profile was also observed [63].

\subsection{Coronary heart disease}

A study conducted in the United States of America concluded that VLCFA were associated with a healthy serum lipid profile (low triglycerides concentration and increased HDL-c) and decreased cardiovascular risk by 52\% [64].

\subsection{Diabetes mellitus}

An experimental study in mice with type II diabetes, treated with Octacosanol (the major component of policosanol), showed that the animals attenuated hypertriglyceridemia and total cholesterol concentration, as well as the 
concentration of lipoperoxides in serum and liver tissue, indicating an improvement in hyperlipidemia and oxidative stress in treated animals [65]..

Policosanol supplementation decreased the concentration of glucose and cholesterol, as well as the activity of the enzyme 3 Hydroxymethyl Glutaryl CoA Reductase in a model of rats fed diets rich in cholesterol [66].

The concentration of circulating VLCFA-derived phospholipids is associated with a lower risk of diabetes and a decrease in triglycerides in the elderly [67].

Treatment with Policosanol produced a significant reduction in total cholesterol, LDL-c and the HOMA index (Homeostatic Model Assessment) ( $\mathrm{p}<0.002$ ) indicating an effect on insulin resistance and glucose metabolism in patients with fatty liver. A non-significant trend, but a marked reduction in transaminases, triglycerides, and body mass index was also found in these patients [68].

It has been observed in a clinical trial that treatment with Policosanol has a lowering effect on glycosylated hemoglobin in addition to a better composition of serum lipids in non-insulin-dependent diabetic patients, [69]. which has been repeated in another trial with diabetic patients [70].

\subsection{Metabolic syndrome}

A population study carried out in South Korea demonstrated the association of VLCFA in the improvement of the metabolic syndrome. The results indicated that dietary ingestion of VLCFA is significantly associated with a decrease in circulating triglycerides and negatively associated with the risk of metabolic syndrome compared to subjects with low VLCFA intake among other cardiovascular risk markers [71].

In a randomized controlled study held in Cuba, Policosanol was able to improve oxidative stress in patients with metabolic syndrome in addition to a beneficial effect on the lipid profile been safe and well tolerated [72].

The treatment with a product containing policosanol (Armolipid) for six months improved oxidative stress and serum lipid profile in patients with metabolic syndrome and it is suggested that the risk and development of atherosclerosis is reduced, particularly in small and dense LDL-c patients [73].

\subsection{Arterial hypertension}

Consumption of Policosanol for 12 weeks in healthy subjects significantly reduced systolic and diastolic blood pressure, as well as mean arterial pressure in 12 weeks of treatment, and also decreased total cholesterol, LDL-c and triglycerides while increasing HDL-c [74].

A large study on the results reported in the literature indicates a significant hypotensive effect of Policosanol on systolic $(\mathrm{p}<0.001)$ and diastolic $(\mathrm{p}<0.013)$ pressure. However, longer-term studies are suggested [75].

\section{Conclusion}

The increase in the global population over 60 years of age and the CNCDs associated with the increase in life expectancy are a cause for concern throughout the world. There is a need for a health culture that promotes healthy nutritional habits and the systematic practice of physical activity, as well as the use of medicines of natural origin that can contribute to the prevention of CNCDs associated with old age. Policosanol is a medicine of natural origin with proven effects on the mechanisms that regulate the aging process that, in addition, prevents or attenuates the development of different CNCDs, so it is suggested to be included among the medicines of natural origin that can contribute to a healthier aging.

\section{Compliance with ethical standards}

\section{Financial disclosure}

A research grant of the National Centre for Scientific Research supported the conduction of these studies. No financial interests influence the conclusions or outcome of this study report. No author has received financial support from a commercial source. 


\section{Conflict of interest}

The authors declare that there is no conflict of interest in relation to this work.

\section{References}

[1] Sun X, Chen WD, Wang YD. $\beta$-Amyloid: the key peptide in the pathogenesis of Alzheimer's disease. Frontiers in Pharmacology. 2015; 6: 221.

[2] World Health Organization. World report on ageing and health. World Health Organization. 2015.

[3] Habib SH, Saha S. Burden of non-communicable disease: global overview. Diabetes \& Metabolic Syndrome: Clinical Research \& Reviews. 2010; 4(1): 41-47.

[4] Nikhra V. Metabolic Disequilibrium and Aging: Modifying Favorably with Calorie Restriction and Calorie Restriction Mimetic. Aging. 2018; 21: 52-55.

[5] You M, Cao Q Liang X, Ajmo JM, Ness GC. Mammalian sirtuin 1 is involved in the protective action of dietary saturated fat against alcoholic fatty liver in mice. The Journal of Nutrition. 2008; 138(3): 497-501.

[6] Chang C, Su H, Zhang D, Wang Y, Shen Q, Liu B, Liu W. AMPK-dependent phosphorylation of GAPDH triggers Sirt1 activation and is necessary for autophagy upon glucose starvation. Molecular Cell. 2015; 60(6): 930-940.

[7] Åhlund K, Ekerstad N, Bäck M, Karlson BW, Öberg B. Preserved physical fitness is associated with lower 1-year mortality in frail elderly patients with a severe comorbidity burden. Clinical Interventions in Aging. 2019; 14: 577-581.

[8] Morris BJ, Willcox BJ, Donlon TA. Genetic and epigenetic regulation of human aging and longevity. Biochimica et Biophysica Acta (BBA)-Molecular Basis of Disease. 2019; 1865(7): 1718-1744.

[9] Ungvari Z, Tarantini S, Donato AJ, Galvan V, Csiszar A. Mechanisms of vascular aging. Circulation Research. 2018; 123(7): 849-867.

[10] Willcox BJ, Donlon TA, He Q, Chen R, Grove JS, Yano K, Curb JD. FOXO3A genotype is strongly associated with human longevity. Proceedings of the National Academy of Sciences. 2008; 105(37): 13987-13992.

[11] Huang H, Tindall DJ. Dynamic FoxO transcription factors. Journal of Cell Science. 2007; 120(15): 2479-2487.

[12] Partridge L, Brüning JC. Fork head transcription factors and ageing. Oncogene. 2008; 27(16): 2351-2363.

[13] Salminen A, Kaarniranta K. AMP-activated protein kinase (AMPK) controls the aging process via an integrated signaling network. Ageing Research Reviews. 2012; 11(2): 230-241.

[14] Khorraminejad-Shirazi M, Farahmandnia M, Kardeh B, Estedlal A, Kardeh S, Monabati A. Aging and stem cell therapy: AMPK as an applicable pharmacological target for rejuvenation of aged stem cells and achieving higher efficacy in stem cell therapy. Hematology/oncology and stem cell therapy. 2018; 11(4): 189-194.

[15] Leidal AM, Levine B, Debnath J. Autophagy and the cell biology of age-related disease. Nature Cell Biology. 2018; 20(12): 1338-1348.

[16] Cyntia JK, Stambler I. Evolutionary theories of aging. Nature. 2010; 464(7288): 504-512.

[17] Titorenko VI, Terlecky SR. Peroxisome metabolism and cellular aging. Traffic. 2011; 12(3): 252-259.

[18] Ponnusamy S, Alderson NL, Hama H, Bielawski J, Jiang JC, Bhandari R, Ogretmen B. Regulation of telomere length by fatty acid elongase 3 in yeast: involvement of inositol phosphate metabolism and Ku70/80 function. Journal of Biological Chemistry. 2008; 283(41): 27514-27524.

[19] Micoogullari Y, Basu SS, Ang J, Weisshaar N, Schmitt ND, Abdelmoula WM, Hanna J. Dysregulation of very-longchain fatty acid metabolism causes membrane saturation and induction of the unfolded protein response. Molecular Biology of the Cell. 2020; 31(1): 7-17.

[20] Barry DS, O'Keeffe GW. Peroxisomes: the neuropathological consequences of peroxisomal dysfunction in the developing brain. The International Journal of Biochemistry \& Cell Biology. 2013; 45(9): 2012-2015.

[21] Clayton PT. Clinical consequences of defects in peroxisomal $\beta$-oxidation. Biochemical Society Transactions. 2001; 29(2): 298-305. 
[22] Reddy JK, Hashimoto T. Peroxisomal $\beta$-oxidation and peroxisome proliferator-activated receptor $\alpha$ : an adaptive metabolic system. Annual Review of Nutrition. 2001; 21(1): 193-230.

[23] Gonzalez FJ, Peters JM, Cattley RC. Mechanism of action of the nongenotoxic peroxisome proliferators: role of the peroxisome proliferator-activated receptor $\alpha$. Journal of the National Cancer Institute. 1998; 90(22): 1702-1709.

[24] Hostetler HA, Kier AB, Schroeder F. Very-long-chain and branched-chain fatty acyl-CoAs are high affinity ligands for the peroxisome proliferator-activated receptor $\alpha$ (PPAR $\alpha$ ). Biochemistry. 2006; 45(24): 7669-7681.

[25] Echeverría F, Ortiz M, Valenzuela R, Videla LA. Long-chain polyunsaturated fatty acids regulation of PPARs, signaling: Relationship to tissue development and aging. Prostaglandins, Leukotrienes and Essential Fatty Acids. 2016; 114: 28-33.

[26] Maeba R, Maeda T, Kinoshita M, Takao K, Takenaka H, Kusano J, Teramoto T. Plasmalogens in human serum positively correlate with high-density lipoprotein and decrease with aging. Journal of Atherosclerosis and Thrombosis. 2007; 14(1): 12-18.

[27] Sutter I, Velagapudi S, Othman A, Riwanto M, Manz J, Rohrer L, von Eckardstein A. Plasmalogens of high-density lipoproteins (HDL) are associated with coronary artery disease and anti-apoptotic activity of HDL. Atherosclerosis. 2015; 241(2): 539-546.

[28] You M, Cao Q, Liang X, Ajmo JM, Ness GC. Mammalian sirtuin 1 is involved in the protective action of dietary saturated fat against alcoholic fatty liver in mice. The Journal of Nutrition. 2008; 138(3): 497-501.

[29] Li ZH, Lv YB, Zhong WF, Gao X, Byers Kraus V, Zou MC, Mao C. High-density lipoprotein cholesterol and all-cause and cause-specific mortality among the elderly. The Journal of Clinical Endocrinology \& Metabolism. 2019; 104(8): 3370-3378.

[30] Menéndez R, Fernandez SI, Del Rio A, Gonzalez RM, Fraga V, Amor AM, Mas R. Policosanol inhibits cholesterol biosynthesis and enhances low density lipoprotein processing in cultured human fibroblasts. Biological Research. 1994; 27(3-4): 199-203.

[31] Banerjee S, Ghoshal S, Porter TD. Activation of AMP-kinase by policosanol requires peroxisomal metabolism. Lipids. 2011; 46(4): 311-321.

[32] Nam DE, Yun JM, Kim D, Kim OK. Policosanol attenuates cholesterol synthesis via AMPK activation in Hypercholesterolemic rats. Journal of Medicinal Food. 2019; 22(11): 1110-1117.

[33] Lee EY, Yoo JA, Lim SM, Cho KH. Anti-aging and tissue regeneration ability of policosanol along with lipidlowering effect in hyperlipidemic zebrafish via enhancement of high-density lipoprotein functionality. Rejuvenation Research. 2016; 19(2): 149-158.

[34] Cho KH, Bae M, Kim JR. Cuban sugar cane wax acid and policosanol showed similar atheroprotective effects with inhibition of LDL oxidation and cholesteryl ester transfer via enhancement of high-density lipoproteins functionality. Cardiovascular Therapeutics. 2019; 6: 85-88.

[35] Vance JE. Lipoproteins secreted by cultured rat hepatocytes contain the antioxidant 1-alk-1-enyl-2acylglycerophosphoethanolamine. Biochimica et Biophysica Acta (BBA)-Lipids and Lipid Metabolism. 1009; 1045(2): 128-134.

[36] Menéndez R, Más R, Amor AM, González RM, Fernández JC, Rodeiro I, Jiménez S. Effects of policosanol treatment on the susceptibility of low density lipoprotein (LDL) isolated from healthy volunteers to oxidative modification in vitro. British Journal of Clinical Pharmacology. 2000; 50(3): 255-262.

[37] Rizzo WB, Craft DA, Somer T, Carney G, Trafrova J, Simon M. Abnormal fatty alcohol metabolism in cultured keratinocytes from patients with Sjögren-Larsson syndrome. Journal of Lipid Research. 2008; 49(2): 410-419.

[38] Fernández JC, Illnait J, Fernández L, Gámez R, Mendoza S, Alvarez E, Orta SD. Long-Term Therapy with Cuban Policosanol on Hypercholesterolemic Elder Patients: Analysis by Gender. International Research Journal of Pharmacy and Medical Science. 2020; 3(5): 11-17.

[39] Balistreri CR. Anti-inflamm-ageing and/or anti-age-related disease emerging treatments: a historical alchemy or revolutionary effective procedures?. Mediators of Inflammation. 2018; 6: 1-13.

[40] Singh J, Suhail H, Giri S. Loss of AMP-activated protein kinase induces mitochondrial dysfunction and proinflammatory response in unstimulated Abcd1-knockout mice mixed glial cells. Mediators of Inflammation. 2015; 3: 41-44. 
[41] Noa M, De la Rosa MC, Mas R. Effect of Policosanol on Foam-cell Formation in Carrageenan-induced Granulomas in Rats. Journal of Pharmacy and Pharmacology. 1996; 48(3): 306-309.

[42] Pirro M, Mannarino MR, Ministrini S, Fallarino F, Lupattelli G, Bianconi V, Mannarino E. Effects of a nutraceutical combination on lipids, inflammation and endothelial integrity in patients with subclinical inflammation: a randomized clinical trial. Scientific Reports. 2016; 6(1): 1-9.

[43] Jung CK, Youm JH. The effect of 12-weeks combined training and policosanol supplementation inflammatory and maker and leptin in obese women. Journal of Digital Convergence. 2015; 13(4): 387-393.

[44] Liu S, Tan MY, Zhao SP, Rong H. Effects of policosanol on serum lipids and heme oxygenase-1 in patients with hyperlipidemia. Zhonghua Xin Xue Guan Bing Za Zhi. 2012; 40(10): 840-843.

[45] Mendoza S, Noa M, Mas R, Mas R, González JE, Arango E. Efectos del D-003 sobre daño endotelial inducido por citrato de sodio en ratas. Revista CENIC. Ciencias Biológicas. 2010; 41(3): 165-168.

[46] Noa M, Más R, Lariot C. Protective effect of policosanol on endothelium and intimal thickness induced by forceps in rabbits. Journal of Medicinal Food. 2007; 10(3): 452-459.

[47] Castano G, Mas R, Arruzazabala ML, Noa M, Illnait J, Fernandez JC, Menendez A. Effects of policosanol and pravastatin on lipid profile, platelet aggregation and endothelemia in older hypercholesterolemic patients. International Journal of Clinical Pharmacology Research. 1999; 19(4): 105-116.

[48] Li C, Ding Y, Si Q, Li K, Xu K. Multiple functions of policosanol in elderly patients with dyslipidemia. Journal of International Medical Research. 2020; 48(7): 1-9.

[49] Menéndez R, Fraga V, Amor AM, González RM, Más R. Oral administration of policosanol inhibits in vitro copper ion-induced rat lipoprotein peroxidation. Physiology \& Behavior. 1999; 67(1): 1-7.

[50] Fraga V, Menendez R, Amor AM, González RM, Jiménez S, Mas R. Effect of policosanol on in vitro and in vivo rat liver microsomal lipid peroxidation. Archives of Medical Research. 1997; 28(3): 355-360.

[51] Ohashi K, Ishikawa H, Ohta Y. Octacosanol ameliorates hyperlipidemia and oxidative stress in KKAy mice with type 2 diabetes. Journal of Analytical Bio-Science. 2011; 34(3): 1-9.

[52] Castaño G, Menendez R, Mas R, Amor A, Fernandez JL, Gonzalez RL, Alvarez E. Effects of policosanol and lovastatin on lipid profile and lipid peroxidation in patients with dyslipidemia associated with type 2 diabetes mellitus. International Journal of Clinical Pharmacology Research. 2002; 22(3-4): 89-99.

[53] Kaushik TS, Ohno H, Wang Y, Motomura K, Shimura T, Okajima Y. Shimano H. Octacosanol and policosanol prevent high-fat diet-induced obesity and metabolic disorders by activating brown adipose tissue and improving liver metabolism. Liver. 2019; 9(5169): 1-12.

[54] Fernández L, Más R, Illnait J, Fernández JC. Policosanol: results of a postmarketing surveillance study of 27,879 patients. Current Therapeutic Research. 1998; 59(10): 717-722.

[55] Fernández S, Mas R, Illnait J, Fernandez JC, Fernandez L, Alvarez E. A pharmacological surveillance study of policosanol tolerability in elderly. Am J Ger Pharmacotherapy. 2004; 2: 219-229.

[56] Lee IM, Shiroma EJ, Lobelo F, Puska P, Blair SN, Katzmarzyk PT. Lancet Physical Activity Series Working Group Effect of physical inactivity on major non-communicable diseases worldwide: an analysis of burden of disease and life expectancy. Lancet. 2012; 380(9838): 219-229.

[57] Kohl LL, Harold W, Craig L, Lambert V, Inoue S, Alkandari, JR, Leetongin G, Kahlmeier S. The pandemic of physical inactivity: global action for public health. Lancet. 2012; 380(9838): 294-305.

[58] Ekblom Ö, Ekblom-Bak E, Rosengren A, Hallsten M, Bergström G, Börjesson M. Cardiorespiratory fitness, sedentary behaviour and physical activity are independently associated with the metabolic syndrome, results from the SCAPIS pilot study. PloS one. 2015; 10(6): 1-18.

[59] Fontani G, Lodi L, Migliorini S, Corradeschi F. Effect of omega-3 and policosanol supplementation on attention and reactivity in athletes. Journal of the American College of Nutrition. 2009; 28(4): 473S-481S.

[60] Reyes R, Illnait J, Más R, Fernández L, Fernández J. El vasoactol sobre el rendimiento físico en ancianos. Revista CENIC Ciencias Biológicas. 2000; 31(2): 135-139.

[61] Pérez P, Illnait J, Fernández L, Mesa M, Fernández J, Gámez R, Jardines Y. Effects of D-003 (Sugarcane Wax Acids) on the Physical Exercise on Static Bicycle Test Lat Am J Pharm. 2010; 29(2): 263-270. 
[62] Arruzazabala ML, Molina V, Carbajal D, Valdés S, Más R. Effect of policosanol on cerebral ischemia in Mongolian gerbils: Role of prostacyclin and thromboxane A2. Prostaglandins, Leukotrienes and Essential Fatty Acids. 1993; 49(3): 695-697.

[63] Pengfei Cheng, Jingxia Wang, Weihua Shao, Meiling Liu, Hui Zhang. Can dietary saturated fat be beneficial in prevention of stroke risk? A meta-analysis. Neurol Sci. 2016; 37: 1089-1098.

[64] Sanchez J, Illnait J, Mas R, Perez Y, Mendoza S, Cabrera C, Fernández L, Mesa M, Fernández J, Oyarzabal A, Molina $\mathrm{V}$, Jimenez S, Reyes P. Effects of policosanol plus aspirin therapy on the neurological recovery and plasma oxidative markers of patients with ischemic stroke. IOSR Journal of Pharmacy. 2013; 4: 31-40.

[65] Malik VS, Chiuve SE, Campos H, Rimm EB, Mozaffarian D, Hu FB, Sun Q. Circulating very-long-chain saturated fatty acids and incident coronary heart disease in US men and women. Circulation. 2015; 132(4): $260-268$.

[66] Ohashi K, Ishikawa H, Ohta Y. Octacosanol ameliorates hyperlipidemia and oxidative stress in KKA mice with type 2 diabetes. Journal of Analytical Bio-Science. 2011; 34(3): 223-238.

[67] Lee JY, Choi HY, Kang YR, Chang HB, Chun HS, Lee MS, Kwon YI. Effects of long-term supplementation of policosanol on blood cholesterol/glucose levels and 3-hydroxy-3-methylglutaryl coenzyme a reductase activity in a rat model fed high cholesterol diets. Food Science and Biotechnology. 2016; 25(3): 899-904.

[68] Lemaitre RN, Fretts AM, Sitlani CM, Biggs ML, Mukamal K, King IB, Mozaffarian D. Plasma phospholipid very-longchain saturated fatty acids and incident diabetes in older adults: the Cardiovascular Health Study. The American Journal of Clinical Nutrition. 2015; 101(5): 1047-1054.

[69] Musto D, Martorelli L, Russo M, Esposito G, Amato MR, Esposito P, Riegler G. Non-alcoholic hepatic steatosis: the role of policosanols in associated hyperlipidemia. Minerva Gastroenterologica e Dietologica. 2010; 56(4): 389395.

[70] Crespo N, Alvarez R, Más R, Illnait J, Fernández L, Fernández JC. Effects of policosanol on patients with noninsulin-dependent diabetes mellitus and hypercholesterolemia: a pilot study. Current Therapeutic Research. 1997; 58(1): 44-51.

[71] Torres O, Agramonte AJ, Illnait J, Ferreiro RM, Fernández L, Fernández JC. Treatment of hypercholesterolemia in NIDDM with policosanol. Diabetes Care. 1995; 18(3): 393-397.

[72] Youn Sue Lee, Yoonsu Cho, Min-Jeon Shin. Dietary long chain Saturated Fatty Acids and metabolic Factors: Findings from the Korea National Health and nutrition examination Survey 2013, Food Science and Biotechnology. 2016; (25): 899-904.

[73] Arteche L, Fernandez JC, Suarez N, Marin J, Alvarez V, Chaviano J, Pedroso VS. Effects of Policosanol in Patients with Metabolic Syndrome: A Six-Month Study. Journal of Endocrinology and Metabolism. 2020; 10(2): 36-44.

[74] Galletti F, Fazio V, Gentile M, Schillaci G, Pucci G, Battista F, Giacovelli G. Efficacy of a nutraceutical combination on lipid metabolism in patients with metabolic syndrome: a multicenter, double blind, randomized, placebo controlled trial. Lipids in Health and Disease. 2019; 18(1): 1-8.

[75] Askarpour M, Ghaedi E, Roshanravan N, Hadi A, Mohammadi H, Symonds ME, Miraghajani M. Policosanol supplementation significantly improves blood pressure among adults: A systematic review and meta-analysis of randomized controlled trials. Complementary Therapies in Medicine. 2019; 45: 89-97. 